Paidéia, 2005, 15(31), 287-297

\title{
AS REDES PESSOAIS SIGNIFICATIVAS COMO INSTRUMENTO DE INTERVENÇÃO PSICOLÓGICA NO CONTEXTO COMUNITÁRIO ${ }^{1}$
}

\author{
Carmen L. Ojeda Ocampo More ${ }^{2}$ \\ Universidade Federal de Santa Catarina
}

\begin{abstract}
Resumo: Este artigo visa apresentar proposta de sistematização do trabalho com redes significativas pessoais em torno de um paciente, e sua ressonância nas pessoas participantes do processo de intervenção psicológica. Buscou-se gerar condições para que os envolvidos na situação de intervenção pudessem ser coconstrutores das mudanças, frente à visão do problema da pessoa que procurou atendimento. $\mathrm{O}$ método foi $\mathrm{o}$ clínico-qualitativo proposto pela “Grounded Theory”. A análise dos casos estudados mostrou a eficácia da intervenção de rede no atendimento a famílias com pacientes psiquiátricos, para os participantes possibilitando entrar em contato com seu potencial de ajuda, para o psicoterapeuta distribuindo a responsabilidade no cuidado da pessoa identificada. O trabalho com a rede pessoal significativa não implica em desistência de outras ações de intervenção ou olhares teóricos, constituindo-se em aporte qualitativo, tanto para o profissional, como para o potencial de ação clínica da psicologia, em variados contextos de atuação.
\end{abstract}

Palavras-chave: redes significativas; intervenção psicológica.

\section{THE SIGNIFICANT PERSONAL NETS AS PSYCHOLOGICAL INSTRUMENT OF INTERVENTION}

\begin{abstract}
This article proposes a model for interventions in the networks of meaningful social relationships around a patient and describes its impact on the participants and on the psychological intervention process. The intention was to provide conditions so that all participants could be co-constructors of change possibilities in relationship to the perception of the problem that provoked the search for treatment. The clinical-qualitative method of "Grounded Theory" was used. The cases analyzed indicated the efficacy of the intervention with the families with psychiatric patients, in providing the network participants the possibility of finding their own potential for helping, for the psychotherapist in the responsibility distribution of the identified person care. The proposal of working with networks of meaningful social relationships does not exclude interventions from other theories. Rather, it increases the possibilities, both for the professionals understanding and for clinical psychology interventions in varied contexts.
\end{abstract}

Key-words: Networks of Meaninful; psychological intervention.

“... temos aberto a porta do consultório, não aos pacientes e seus parentes mais próximos, mas também a cada homem e a cada mulher que possam dar apoio para gerar uma mudança na pessoa que sofre” J. Klefbek (2000).

$\mathrm{Na}$ busca constante de uma escuta contextualizada à luz dos campos de atuação e visan-

\footnotetext{
${ }^{1}$ Recebido para publicação em 19/04/2005 e aceito em 29/07/2005. ${ }^{2}$ Endereço para correspondência: Carmen L. Ojeda Ocampo Moré. Universidade Federal de Santa Catarina, Programa de Pós-Graduação em Psicologia, Departamento de Psicologia - CFH, Trindade, Florianópolis - SC, CEP: 88900-000 , E-mail: cmore@mbox1.ufsc.br
}

do resgatar as potencialidades implícitas nos mesmos, o trabalho com a rede pessoal significativa, constituída pelo conjunto de todas as relações que um indivíduo percebe de forma diferenciada do resto de suas relações, surgiu como um desdobramento de atividades que se desenvolvia na comunidade. À medida que se adentrou na comunidade, foi-se implementando essa prática e buscando novas alternativas de intervenção para responder tanto às necessidades dela, como às dos profissionais. Isto levou a direcionar os estudos para a temática das redes, no sentido de pro- 
curar melhor sistematização e fundamentação de prática, principalmente no contexto público comunitário.

A proposta foi de desenvolver uma pesquisa com a rede pessoal significativa das pessoas, no contexto específico de intervenção psicológico-comunitária, visando evidenciar sua eficácia de gerar condições para todos os envolvidos na situação, de serem co-construtores das possibilidades de mudança, com relação à visão do problema/queixa, pelo qual a pessoa/família procurava atendimento. Assim, o objetivo central deste estudo foi a apresentação de uma proposta de sistematização de trabalho com redes significativas pessoais, sua ressonância nos participantes e no processo de intervenção psicológica. Especificamente, pretendeu-se: avaliar a necessidade de criar uma rede pessoal significativa em torno de uma pessoa com problema, para ampliar as possibilidades de cuidado e responsabilidade pela mesma; avaliar as condições psicológicas de pessoas convidadas a participar de uma rede; gerar condições para compreensão da proposta de trabalho com a rede pessoal significativa, tanto para a solicitante, quanto para todos os envolvidos; avaliar nos integrantes da rede os efeitos do trabalho realizado.

Quando se fala de atuação clínica, aludindo à Psicologia Clínica, não como uma área, ou um rótulo que dá identidade ao Psicólogo, pretende-se visualizá-la como uma estratégia para pensar seres humanos inseridos em seus contextos (Moré, 2000). A busca de fundamentação de novas propostas de intervenção clínica, como a do trabalho com a rede pessoal social significativa, não implica em necessária desistência de outras ações de intervenção ou de outros olhares teóricos, conforme aponta Sluzki, (1997), mas, num aumento das possibilidades da atuação da psicologia, nos mais variados contextos.

\section{Delineamentos teóricos sobre o trabalho com redes}

Fazendo uma análise retrospectiva, verifica-se que a temática de redes sociais já aparecia como objeto de análise e de proposta de intervenção propriamente dita há algum tempo, como mostram Lewin (1952), cuja teoria de campo inclui explicitamente variáveis centradas nas relações informais, e Moreno (1951), o criador do psicodrama, que desenvolveu a técnica do sociograma, para esboçar uma rede de relações.
Na prática clínica, os primeiros trabalhos de destaque sobre redes, no campo da saúde mental e na terapia familiar, remontam à década de 60, nos Estados Unidos, em trabalhos dirigidos às comunidades carentes (Elkaïm,1989). Esta obra reúne os primeiros alicerces teóricos sobre o tema, e traz os trabalhos pioneiros relativos à terapia de rede de diversos autores, em termos de reflexão teórica e de intervenção.

Cabe mencionar também, que a temática das redes sociais tem interfaces com diferentes posturas teóricas e práticas; no campo da práxis comunitária, há os trabalhos de Elkaïm, (1989) e Fuks, (1989); na perspectiva sociológica, tratando dos processos de marginalização, de ruptura de redes de suporte social, quebra do sentido de pertença e referência dos indivíduos nos contextos locais, existem os trabalhos de Castel, (1984) e Sluzki (1997). Observa-se nesses trabalhos a idéia de resgate de um sentimento de pertença a grupos ou comunidades, do espírito de solidariedade e de autogestão grupal.

Na década 90, encontraram-se autores como Dabas (1993), Dabas e Naminovich, (1995), Packman (1995), Sluzki (1996, 1997); Klefbek, (2000), que aprofundam o tema das redes pessoais e sociais em diferentes contextos-clínico-comunitários, e mostram sua importância como instrumento eficaz de intervenção psicológica. No Brasil, especificamente na área da Psicologia Clínica, há uma produção bibliográfica incipiente, e uma influência direta da produção teórica da Argentina, mas podem-se destacar, no campo da Psicologia, os trabalhos de Vasconcelos (1995) e de profissionais que trabalham na perspectiva da terapia familiar.

\section{O surgimento das possibilidades do trabalho de rede: sua conceituação}

As possibilidades do trabalho com a rede pessoal significativa, das pessoas que procuravam por atendimento na área da saúde mental, surgiram em momentos de grande dificuldade da psicoterapia clássica, conforme aponta Elkaïm (1989), em que o problema apresentado não podia ser dissociado do contexto mais amplo das relações em que as pessoas estavam inseridas. Speck (1989.) aponta que: "O fracasso do tratamento obedecia com freqüência ao fato de que trabalhávamos com uma unidade demasiado restringida, à família. Isto nos levou a 
ampliar estas sessões familiares convidando a certos parentes e amigos com capacidade de desempenhar um papel significativo" (p.21).

A evidência dessa limitação nas ações terapêuticas, circunscritas ao espaço tradicional de intervenção, fez com que se abrisse espaço para a inclusão de outras mais próximas do solicitante. Nas experiências iniciais com trabalho de rede (Elkaïm,1989), incluía-se grande número de pessoas, de 15 a 50, relembrando o modelo de cura tribal, exigindo a presença de vários profissionais da saúde, para trabalhar com o grande grupo.

A simbologia da cura tribal aponta para resgatar e buscar soluções através de uma reunião grupal, para o problema de um de seus integrantes, o que potencializa os recursos individuais em favor do outro ou do grupo. De certo modo, assiste-se a um processo de resignificação das relações pessoais significativas, percebendo o potencial de acolhimento.

Desde o começo dos trabalhos com rede na década de 60 , utilizaram-se diferentes terminologias para denominá-la, como: terapia de rede, intervenção de rede e trabalho de rede; mas, há tendência em usar o conceito de intervenção de rede por ser este termo mais preciso, quando se evidencia a necessidade de ampliar para mais pessoas uma determinada proposta de tratamento.

A compreensão de rede pessoal significativa, utilizada neste trabalho, está ancorada tanto na definição de rede social de Speck (1989) que diz:

A rede social é um grupo de pessoas, membros da família, vizinhos, amigos e outras pessoas, com capacidade de aportar uma ajuda e um apoio tão reais como duradouros a um indivíduo ou família. (p.24), como na apresentada por Sluzki (1997) que na ótica da terapia familiar, complementa a anterior:

A rede corresponde ao nicho interpessoal da pessoa e contribui substancialmente para seu próprio reconhecimento como indivíduo e para sua auto-imagem.

A rede pessoal social é a soma de todas as pessoas que o indivíduo percebe ou sente como significativas ou diferentes do universo relacional no qual está inserido. (p42).
Assim, quando se fala de rede pessoal significativa, refere-se a um sistema aberto, constituído pelo conjunto de todas as relações que um indivíduo percebe como significativas, ou diferenciadas do restante. E o sistema aberto alude à possibilidade de troca efetiva com integrantes de outros grupos sociais. Dabas (1993) diz que "As diversas aprendizagens que uma pessoa realiza se potencializam quando são socialmente compartidos na procura de solucionar um problema em comum”. (p.20).

Na perspectiva individual, a rede corresponde a sua matriz interpessoal e contribui para seu reconhecimento como pessoa e sua auto-imagem, sendo uma das chaves da experiência de identidade, bem estar, competência, hábitos de cuidado da saúde e capacidade de adaptação em uma crise. (Sluzki, 1997). Já na perspectiva sócio-relacional, as mudanças na rede social das pessoas constituem um marcador de vicissitudes, a migração, o casamento, o divórcio, o adoecer, bem como a obtenção da cura. Sluzki (1997) faz uma importante afirmação, onde se evidência a relação direta entre qualidade da rede social e a saúde:

"Existem provas fidedignas de que uma rede pessoal estável, sensível, ativa e confiante protege as pessoas das enfermidades, atua como um agente de ajuda e derivação, afeta a pertinência e a rapidez da utilização dos serviços de saúde, acelera os processos de cura e aumenta a sobrevida" (p.67).

A implementação da intervenção de rede, além de abrir novas possibilidades, seja para o profissional como para as pessoas que necessitam de atendimento, evita o "encapsulamento do campo de intervenção” (Dabas, 1993; Klefbek, 2000).

\section{Funções de uma rede pessoal social significativa: importância de seu reconhecimento}

A partir da análise da literatura em torno da temática de redes, principalmente na intervenção clínica, destaca-se a sua efetividade, no que diz respeito ao suporte que pode oferecer para uma pessoa ou família, que se encontram num momento de crise.

A função de uma rede está estreitamente relacionada à qualidade das relações interpessoais estabelecidas, com a família extensa ou com seu entorno social, de onde surgem atributos importantes, 
que poderão configurar a construção de uma rede de suporte pessoal significativa. Por sua vez, a qualidade das relações está necessariamente ancorada na história dos vínculos estabelecidos, na intensidade, freqüência e mutualidade dos mesmos. Sluzki (1997) diz que: "Por exemplo, uma relação com muita história em comum mantém intensidade mesmo se os contatos não forem muito freqüentes" (p58).

De acordo com o tipo de intercâmbio interpessoal entre os membros de uma rede, estabelecem-se suas funções e elas podem ser de: a) Companhia social: realização de atividades conjuntas ou estar juntos em determinadas situações vitais, (doença, morte de alguém). b) Apoio emocional: reação de compreensão, empatia, estímulo e apoio. c) Guia cognitivo: relações que fornecem informação, esclarecem expectativas, proporcionam modelos de papéis. d) Regulação social: relações que neutralizam desvios comportamentais, lembram responsabilidades, favorecem a resolução de conflitos. e) Ajuda material ou de serviços: ajuda profissional específica, incluindo os serviços de saúde e sua equipe. f) Acesso a novos contatos: abertura para a possibilidade de outras relações além das já estabelecidas e que evidenciam seu potencial de vínculo.

Sluzki (1997) chama a atenção para a complexidade destas funções. E, o grande desafio que se coloca ao se trabalhar com famílias na perspectiva de rede está em detectar a função dos integrantes que hão de constituir a mesma, ou seja, investigar o conjunto de comportamentos que sustentam a mutualidade e significação de uma relação, porque determinadas relações podem auxiliar ou impedir a promoção da mudança. Assim, a tarefa do profissional será detectar as que têm um potencial afetivo e pessoal, com capacidade de dar sustentação a uma rede de apoio.

Outro aspecto mencionado na literatura diz respeito ao tamanho de uma rede; de acordo com Sluzki (1997), as de tamanho médio de 8 a 10 pessoas, seriam mais efetivas do que as pequenas ou constituídas por muitas pessoas. Nas muito pequenas, pode acontecer que a questão do "cuidado do outro" se transforme num peso ou sobrecarga, gerando tensão, podendo levar à desistência ou provocar sofrimento psíquico. Nas muito grandes, precisar-se-ia de muitos profissionais para manter a "motivação da rede", pois o problema principal é a dispersão ou perda de interesse no trabalho, quando são muitas pessoas.

Para a construção de uma rede faz-se necessário configurar o que Sluzki (1997) denomina de "Mapa da rede": pessoas significativas no âmbito familiar, na vizinhança, nas relações de trabalho, amizades, a partir das instituições as quais a pessoa tem acesso, ou seja, o objetivo é detectar as pessoas significativas, através das diferentes interelações que o solicitante estabelece em todo o seu contexto familiar e social.

\section{Método}

Trata-se de uma investigação qualitativa, em que se utiliza a técnica de estudo de caso, em que a coleta de dados, assim como a construção de categorias de análise, a partir das quais se sistematizou o procedimento de intervenção proposto, seguiu a perspectiva metodológica da "Grounded Theory", que permite trabalhar com dados de diferentes origens: entrevistas, registros de campo, relatos de observações. (Strauss \& Corbin,1990).

\section{Participantes}

Os participantes surgiram do universo de atendimentos realizados num centro comunitário de saúde e num serviço psicológico público, de uma clínica escola. Para a proposta de sistematização, foram selecionados cinco pessoas/e ou famílias e cinco estudos de casos, nos quais surgiu a possibilidade de construção de redes ${ }^{3}$.

\section{Instrumentos e Procedimentos}

Foram utilizados para a coleta de dados: a) Entrevistas de intervenção psicológica, gravadas, tanto com os solicitantes dos serviços, como com a rede constituída, em encontros grupais, cujo roteiro emergiu do processo de intervenção em torno da queixa ou pedido de ajuda e da busca de informações para a possibilidade de construção de rede. b) complementando o instrumento anterior, e sob a referência metodológica da Grounded Theory, foram feitos registros, escritos pela terapeuta/pesquisadora, das ob-

\footnotetext{
${ }^{3}$ Os mesmos se caracterizam por melhor evidenciar os diferentes momentos do processo de construção e sistematização das redes pessoais significativas, entorno da pessoa que solicitou os serviços, assim como também evidenciam as dificuldades na construção das mesmas.
} 
servações de eventos e de visitas domiciliares. c) registro de relatórios de eventos, solicitados pela pesquisadora a determinados integrantes das redes (estagiária do serviço social, professoras da creche, da escola, orientadoras), para fundamentar o processo de intervenção ${ }^{4}$.

Como esta teoria tem como regra geral que a seleção dos participantes da pesquisa, a coleção de dados e sua análise não devem ser separadas, mas integradas, todos os estudos de casos foram descritos com a maior quantidade de detalhes possível, além das gravações realizadas. Buscou-se a comparação das histórias, procurando os aspectos em comum e as características diferenciais. Desse processo surgiram pontos nucleares que se constituíram em categorias principais de análise. Moré (2000) afirma que

“... apesar das categorias terem um papel de serem organizadoras da leitura da realidade, elas só adquirem seu valor instrumental, em termos de campo de significação e sentido, na medida em que o contexto interacional as legitime como tais” (p.71).

\section{Resultados}

\section{Análise dos dados: a experiência de intervenção de rede pessoal significativa}

A partir do reconhecimento da clientela e da demanda dos serviços, buscou-se verificar a inserção das pessoas na comunidade, direcionando o trabalho para investigar o universo de relacionamentos das pessoas no contexto comunitário e identificar o que Sluzki (1997) e Elkaïm, (1989) denominaram de “conjunto de relações significativas”. Nas redes configuradas em torno de membros dessa comunidade foram encontradas pessoas significativas, que se constituiram em aliados importantes do trabalho, principalmente quando se acompanhava ou atendia aos que haviam sofrido internação em instituição psiquiátrica ou violência infantil.

O relato do caso a seguir mostra a importância de se estar atento ao contexto das redes na comunidade e exemplifica a sistematização de processo de intervenção com redes.

\footnotetext{
${ }^{4}$ Este trabalho se desenvolveu a partir do consentimento dos envolvidos e aprovação do Comitê de Ética em Pesquisa da Universidade.
}

A história de Leopoldina: "Eu gosto muito delas... não queria bater"

Mulher, 41 anos, analfabeta, com 4 filhos menores, residindo no alto do morro, numa casa de madeira precária; marido alcoolatra fazia bicos para sobreviver; ela havia sofrido três internações psiquiátricas, sendo conhecida na comunidade por seus distúrbios de comportamento (gritava, cuspia todo o tempo, vestia muita roupa de lã no verão). As assistentes sociais da creche vieram falar a seu respeito, pois estavam preocupadas com os filhos, que ficavam durante o dia na creche; ela estava apresentando problemas de novo e não queria ir ao hospital ou tomar medicação; batia nas crianças, que não aceitavam botar a roupa de lã pelo calor; também as trancava para que não saissem para brincar. Não obedecia a ninguém e só uma estagiária de assistente social conseguia falar com ela. Então, foi solicitado à estagiária que acompanhasse o pesquisador até a casa onde ela morava com as crianças, quando se foi recebido pelos filhos (9, 6, 5 e 4 anos), que estavam preocupados e choravam com medo de que se pudesse levar a mãe de novo, para o hospital, pois não queriam ficar com o pai, que "era muito ruim”. Muito desconfiada com a presença dos pesquisadores e cuspindo todo o tempo,ela dizia que não ia para o hospital, pois tinha que cuidar dos filhos. Depois das apresentações e de acalmá-la dizendo que não seria levada para o hospital, buscou-se conversar no pátio da casa, e tudo ocorreu através da estagiária, sendo que vários vizinhos se aproximaram para ver o que estava acontecendo. Perguntou-se a ela se havia alguém nessa vizinhança em que ela confiasse e ela falou de uma senhora que tomava conta das crianças, e até dava comida quando "ela ficava mal". Esta senhora estava próxima, observando o trabalho, aproximouse e se apresentou; comentou posteriormente que tomava conta das crianças por pena delas, pois apanhavam muito; diz que várias vezes pediu para a mãe parar de bater nas crianças e esta obedeceu prontamente, sendo que depois chorava muito e dizia que não ia fazer mais aquilo, pois gostava muito das crianças.

A partir do entendimento inicial do caso atendido e da visualização da necessidade da construção de uma rede pessoal significativa, para melhor acolher motivo da queixa principal, estabeleceram-se as seguintes categorias, que se constituem em passos de um processo de intervenção. 


\section{Detectando o surgimento de uma rede}

Este momento configurou-se a partir do pedido de ajuda, seja por parte do solicitante dos serviços, ou dos encaminhadores, vizinhos, ou de pessoas com interesse de ajudar alguém que apresentava crises ou sofrimento passível de ajuda específica.

Tendo como referência a história dessa mulher, a partir da estagiária e da vizinha, iniciou-se a montagem de uma rede, em que a função principal, num primeiro momento, era a de assessorar essas duas pessoas para compreender melhor a situação e encontrar caminhos para que a "paciente identificada", entendida aqui como a que motivou o pedido de ajuda, fosse avaliada novamente por um psiquiatra. Logo após a visita domiciliar, estipularam-se as tarefas a serem realizas em conjunto:a) a estagiária acompanhou a Leopoldina na consulta, no hospital psiquiátrico, para contornar seu medo da internação, utilizando-se o vínculo positivo entre elas; b) a vizinha se prontificou a tomar conta das crianças, atividade que já realizava espontaneamente, antes desta solicitação. A vizinha e a estagiária juntas tornaram-se pessoas fundamentais para o acompanhamento do processo de Leopoldina, controlando o uso da medicacão, a alimentação da mãe e das crianças.

A partir dos diálogos com a estagiária e a vizinha foram detectados os demais integrantes da rede, pela função desempenhada na vida de Leopoldina, evidenciando diferentes histórias de vínculos com ela, e configurando o mapa de rede (Sluzki, 1996). A paciente tinha uma aposentadoria por invalidez e trabalhava fazendo limpeza em casas e bares da comunidade; assim apareceram o dono de um bar, para quem trabalhava uma vez por semana como faxineira, e uma antiga patroa, pessoas que, no discurso da vizinha, também se preocupavam com ela e ofereciam-lhe certa ajuda, quando percebiam que não estava bem. Associaram-se a este grupo ainda duas professoras da creche comunitária, mencionadas pela estagiária, que tinham contato diário com as crianças e viam quando não estavam bem ou a mãe "mostrava-se estranha", ao pegar os filhos na creche. Através de relatório solicitado às professoras, a respeito da observação do relacionamento mãe $x$ filhos, confirmou-se o depoimento da vizinha, de que quando Leopoldina não estava em crise, era uma mãe dedicada e carinhosa, cuidando e acompanhando os filhos à creche.
Assim, a rede pessoal significativa de Leopoldina ficou configurada pela estagiária do Serviço Social, 2 professoras da creche, a vizinha, antiga patroa, dono do bar, psicóloga, lembrando-se que a função dos integrantes da rede depende da qualidade de seus intercâmbios (Sluzki,1997); de certo modo, neste caso, eles já desempenhavam funções antes da pesquisa, como a de "reguladora social" por parte da vizinha, das professoras, atentas aos comportamentos de Leopoldina; de "apoio emocional” pela estagiária, e de "ajuda material e de serviços” pela antiga patroa, e o dono do bar.

Da visualização destas funções, foi feito um convite, através de contato individual, a essas pessoas para participarem de uma reunião no Centro de Saúde para dialogar a respeito de Leopoldina, sob a coordenação do pesquisador. Concomitante a estes contatos, ela recebeu atendimento ambulatorial no Hospital Psiquiátrico, onde foi medicada, acompanhando-se sua evolução, através de visitas domiciliares.

\section{Convidando as pessoas para uma reunião}

Este era um momento em que se começava, simbolicamente, a amarrar os nós da rede em torno de objetivos do trabalho em comum. As pessoas acima citadas compareceram à reunião, sendo que a antiga patroa e o dono do bar mencionaram certa estranheza e curiosidade inicial pelo convite feito. Foi comentado o encontro com Leopoldina e como se havia chegado a eles, realçando principalmente, a percepção sobre a função deles no caso, delineando o objetivo de trabalho possível e o porque da construção da rede. Esclareceu-se que a participação era voluntária e solicitou-se, nessa primeira reunião, que não respondessem ao pedido de ajuda realizado, pensassem na solicitação, e nas possibilidades reais e concretas de participar. Para a estagiária, as professoras e a vizinha, o convite foi aceito como algo já esperado, em função dos diálogos anteriores; no entanto, para o dono de bar e a antiga patroa, foi de certo modo diferente, pois comentaram que nunca haviam recebido um convite desse tipo, porém que estavam curiosos em saber no que poderiam ajudar; um segundo encontro grupal foi marcado para a semana seguinte com o aval de todos. Salienta-se a importância destes encontros para avaliar o potencial de acolhi- 
mento de cada um e as características de personalidade dos envolvidos.

\section{Ampliando o conhecimento da rede com relação ao problema}

Após os dois encontros grupais iniciais e tendo a confirmação dos participantes para a formação da rede, passou-se para o momento em que se ampliaram os conhecimentos da mesma com relação ao problema e aos objetivos do trabalho a ser realizado em conjunto. Todas as dúvidas quanto aos comportamentos ou "reações estranhas" de Leopoldina foram discutidas, aspectos estes muito presentes para a antiga patroa, que viu episódios de crise e o temia que voltassem no momento que estivesse trabalhando em sua casa. Quando as dúvidas e temores foram vencidos, passou-se para o quarto momento que se caracteriza por trazer à tona as possibilidades de cada um dos integrantes. Foi acordado para a semana seguinte outro encontro grupal, para dar continuidada à última temática.

\section{Levantando possibilidades de ações em conjunto}

Este momento foi se delineando nos objetivos e quando se ampliava o conhecimento a respeito do problema. Assim, em conjunto, levantou-se o que cada um poderia fazer por Leopoldina, de forma a não interferir no cotidiano deles e não gerar ansiedade ou angústia na realização da tarefa. Ficaram estipuladas as seguintes atividades: a vizinha continuaria a cuidar, mantendo-se atenta, das crianças e da relação de Leopoldina com elas, o que já fazia antes dada a proximidade de sua casa; cuidaria ainda, junto com a estagiária, da alimentação e da medicação. As professoras, no contexto escolar, prestariam atenção às crianças, tanto no seu comportamento, como na alimentação e providenciariam junto ao centro comunitário roupas e sapatos para as mesmas. O dono do bar se prontificou a dar trabalho quando ela se recuperasse, de limpeza da área do bar e dos banheiros e em troca daria dinheiro ou sanduíches para ela e as crianças jantarem. A antiga patroa, se prontificou a dar trabalho de limpeza externa da casa; ela tinha temor das crises ocorrendo dentro de sua casa, mas queria muito ajudar e então estipulou que daria um serviço semanal de limpeza de garagens e áreas aber- tas, pagando uma diária e se preocuparia em arranjar roupas para ela. A importância do trabalho para Leopoldina estaria no fato de ser um meio de mantêla ocupada, numa atividade específica e sustentar um nível de relacionamentos, necessários tanto para dar continuidade aos existentes quanto para impulsionar novos. Para a terapêuta/pesquisadora ficou, além da coordenação da rede estabelecida, a tarefa de acompanhar a adesão ao tratamento e ver a evolução de Leopoldina, que incluía visitas domiciliares e realização de encontros de todos os integrantes da rede, para avaliar o andamento do trabalho; determinou-se que as reuniões para acompanhar o processo de recuperação seriam mensais, até que Leopoldina estivesse engajada nas suas atividades.

Foi sinalizado para a rede, que o trabalho grupal tinha objetivos específicos a cumprir, visando um melhor acompanhamento e inserção de Leopoldina na comunidade, e que, uma vez cumpridos, os encontros grupais terminariam. A finalidade disto foi não criar a expectativa da obrigação de encontros a longo prazo. Pretendia-se que o grupo continuasse de modo espontâneo, sem coordenação, uma vez que eles já sabiam o que fazer e podiam gerar condições para novos contatos na comunidade, apoiando Leopoldina.

\section{Avaliando os efeitos do trabalho por parte dos participantes da rede}

Este momento do processo se caracterizou, em termos simbólicos, como o movimento que mantém a sustentação da rede. Além das visitas domiciliares realizadas, durante o processo de recuperação da crise, foram feitos dois encontros individuais, com Leopoldina, logo após o reinício de suas atividades. Falou-se sobre o grupo de pessoas que estavam se reunindo para ajudar, com trabalho, roupas, comidas, e propôs-se um encontro dela com todos. Isto foi fundamental, para resgatar a síntese do trabalho realizado e avaliar como estavam os integrantes da rede, junto com a pessoa que motivou a mesma. Além de agradecer a todos, Leopoldina teve a oportunidade de visualizar um grupo de pessoas realmente interessadas em ajudar e descobrir que não estava só, nessa comunidade.

Ficou acordado mais um encontro grupal mensal, que aconteceu sem a presença de Leopoldina, e 


\section{Carmen L. Ojeda Ocampo More}

avaliou-se a necessidade de continuação, no mês subsequente, sendo determinado que fosse o último. Estes momentos foram de muita emoção para todos os envolvidos na rede, expressa em seus depoimentos, ao perceberem que "dando tão pouco", podiam ajudar efetivamente uma pessoa através de um trabalho em conjunto. Evidenciou-se o sentimento de solidariedade e a riqueza do mesmo para a condição de seres humanos.

Constatou-se que reconhecer o contexto em que a pessoa vivia, além de ser um elemento da construção do significado nas conversações, ampliava os horizontes sobre novas alternativas psicoterapêuticas, conforme Sluzki (1997), no seu trabalho com a rede social; o foco da atenção deixou de ser a pessoa com distúrbios para ser a rede constituída.

A instrumentalização de redes pessoais significativas nos casos que envolvem pacientes psiquiátricos, é eficaz no sentido de auxiliar o trabalho de uma equipe de saúde mental, principalmente na distribuição do cuidado destinado ao paciente, através de pessoas significativas da comunidade.

\section{Outras possibilidades de formar redes pessoais significativas}

Delineiam-se brevemente, outros exemplos de formação de redes destacando suas peculiaridades, assim como também exemplos em que sua formação foi inviável.

\section{Formando rede para a queixa de fracasso escolar}

A temática da queixa de fracasso escolar foi uma das maiores demandas, tanto no Centro de Saúde Comunitário, como no Serviço de Psicologia Público, devido à falta de profissionais psicólogos na rede do contexto escolar, levando as escolas da comunidade a recorrerem a outros serviços para melhor acolher o aluno e suas famílias.

Tendo como referência os passos anteriormente apresentados para a formação de rede, reuniu-se, em torno de um aluno com queixa de fracasso escolar, trazido para atendimento pela família, através de encaminhamento da escola, as pessoas que, após análise, surgiram como significativas para formar uma rede, sendo o aluno o principal guia das ações. Destaca-se que a família, representada pelo pai e a mãe, mostrou-se preocupada com o filho e com o proble- ma do fracasso escolar, evidenciando sua motivação para o engajamento na proposta de trabalho. $\mathrm{O}$ filho era o do meio, de nove anos e os pais eram pessoas de instrução primária incompleta, que haviam tido mudanças de moradia e local, na busca de melhores condições de trabalho, levando aos filhos a freqüentar diferentes escolas.

Assim a rede, que se configurou em torno do aluno foi constituída pela orientadora pedagógica, a professora da educação física, (figura muito positiva de referência), uma vizinha de 15 anos que cuidava do aluno e do irmão mais novo, quando a mãe trabalhava em determinados períodos, o irmão mais velho de 14 , o pai e a mãe e o pesquisador, enquanto terapeuta. Seguindo o processo de sistematização para formação da rede, cada pessoa tinha uma atividade a desempenhar junto ao aluno identificado, dentro de suas possibilidades e competências.

Foram realizadas duas reuniões com a rede completa e o aluno e três com a rede em separado, pai, mãe, filho mais velho, a vizinha e a orientadora, e outra com a vizinha, orientadora, professora de educação física. Em conseqüência das dificuldades de horário trabalhou-se com a rede ora inteira, ora em separado, porém sempre retomando e deixando claros os objetivos da mesma. Destaca-se que a professora que gerou a queixa inicial foi informada, por parte da orientadora, da formação da rede coordenada pelo pesquisador solicitando-lhe um relatório simples escrito, sobre a percepção do aluno na sala de aula e a necessidade do encaminhamento.

A análise do trabalho desta rede revelou vários aspectos, no sentido das conseqüências que essa experiência gerou nos seus integrantes, no aluno e também na professora que havia feito a queixa inicial sobre fracasso escolar, "como algo difícil” de superar em sala de aula.

a) Após saber do trabalho que se estava fazendo, a professora mudou seu relacionamento com o aluno na sala de aula, o que foi evidenciado por ele, dizendo que ela estava "melhor", "diferente”, “mais boazinha", "consigo fazer perguntas...". Acredita-se que a mudança na postura da professora aconteceu por ela perceber que o aluno estava sendo cuidado.

b) Quanto ao aluno, a possibilidade de resignificar o rótulo de fracasso escolar, não como 
algo impossível de superar, mas compreender que muitas coisas ele não sabia ou não havia aprendido nas escolas anteriores, levou-o a descobrir seu potencial tanto pedagógico, como de mobilização das pessoas em torno de si, o que se evidenciou quando afirmou que a rede era "legal" e que "não imaginei que poderiam me ajudar...”.

c) Com relação aos integrantes, ressalta-se sua surpresa pela proposta de trabalho. Quando começaram a ver os efeitos da atuação da rede, sentiram-se reconhecidos, porém, numa ótica diferente, a do reconhecimento, através da tarefa desempenhada, das potencialidades de cada um. Isto se evidenciou no relato da vizinha que auxiliava nas tarefas da escola; sua percepção era de que essa atividade tinha pouca importância e ficava insegura por não saber se seu trabalho estava bem feito; então, após a experiência de participar da rede, alegou sentir-se reconhecida e que poderia seguir se aperfeiçoando na atividade de ensinar.

d) Com relação ao sistema familiar, houve resignificação das relações familiares, a partir das possibilidades que cada um tinha para oferecer ao outro e não na ótica da cobrança e incompetência; gerou-se, então, um novo patamar de diálogos e possibilidades.

e) Quanto ao trabalho do profisional, conforme apontado antes, a experiência referendava a importância da distribuição da responsabilidade no cuidado de outro, já que muitas vezes fica-se encapsulado nos espaços de intervenção, assumindo uma responsabilidade profissional de certo modo utópica, pois ela tem limitações reais em termos de potencial de mudança.

Estes dados e reflexões vão ao encontro do apontado por autores como Elkaïm, (1989); Klefbek, (2000); Sluzki, (1997) e Speck (1989), quando aludem à abertura do espaço de intervenção para além da família e para outras possibilidades de ajuda, principalmente quando os recursos se tornam insuficientes para solucionar um problema que tem estreitas implicações com outros sistemas além do terapêutico.

É importante aqui, mencionar Sluzki, (1997) quando afirma que o trabalho com a rede significativa se constitui numa alternativa possível, ou seja, não implica em abandonar a proposta de atuação principal. O trabalho com a rede significativa, em certas situações, significa não reduzir as possibilidades de atuação apenas à esfera do psicológico individual.

\section{Formando rede sem ter motivação para a ajuda: criando caminhos para a motivação}

Esta experiência de formação de rede deu-se em torno de uma paciente que havia tido um surto psicótico, morava na comunidade, com 3 filhos, que pouco permaneciam em casa, pois trabalhavam. Quando se analisou o caso, percebeu-se uma rede significativa em torno dela, que incluía pessoas além da família. No entanto, diálogos com os integrantes da família mostraram desmotivação ou resistência, tanto para auxiliar a paciente, como para o trabalho, pois não havia uma compreensão efetiva do que estava acontecendo com ela.

Após várias reuniões com a família, vencendo preconceitos frente à doença mental, ela aceitou a ajuda de pessoas alheias, mas que eram significativas para a paciente. Depois do entendimento do que estava acontecendo com a mãe, foram os filhos que propuseram retomar a proposta de constituição de rede que se havia mencionado como possibilidade de intervenção, para melhor acompanhar a paciente em seu tratamento. Neste caso a rede ficou constituída por uma assistente social, do serviço onde a paciente trabalhava, uma colega de trabalho, uma cunhada que morava próximo, os três filhos e o pesquisador.

Este caso evidencia as dificuldades para a constituição de rede, no sentido de que, como profissionais se pode detectar e visualizar a rede na comunidade, porém se faz necessário todo um trabalho de acompanhamento inicial da pessoa e seus responsáveis, para a aceitação, pois se assim não fosse, não se poderia constituír a mesma.

\section{Na impossibilidade de formar redes pessoais significativas}

Este relato é sobre a experiência de impossibilidade de alguém participar de uma rede pessoal significativa. O paciente era um adulto jovem de 22 anos, solteiro, estudante que compartilhava sua moradia com outros colegas. Sua família morava em outro estado e ele procurou atendimento a pedido de uma amiga, devido às suas manias, comportamentos e "pensamentos de querer experimentar a vivência da morte”. Após análise dos primeiros dados, o paciente foi identificado como bordeline e que havia necessidade de interconsulta com psiquiatra. Quando solicitado 
alguém da família ou responsável, para informar sobre a proposta de trabalho e seu encaminhamento, ele falou da amiga como pessoa mais próxima, alegando que a família morava muito longe.

Após contato inicial com a amiga, ela se apresentou solícita e disposta a ajudar, no entanto, embora desejasse ajudar ela estava assustada com os comportamentos do amigo, e frágil para lidar com a situação. Assim, foi vista somente a possibilidade de acompanhar na interconsulta. Cabe mencionar, que mesmo não fazendo parte do trabalho tentar implementar uma rede, e entendendo que mobilizar uma pessoa para um pedido era entrar no terreno da ética profissional, propos-se outros dois encontros para acolhê-la no seu desejo de ajudar, levando em conta que seu medo, de que tinha consciência, a deixava com sentimento de culpa. Destacou-se o que ela já havia dado ao paciente, mobilizando-o para buscar atendimento, sua disponibilidade para acompanhá-lo na interconsulta; também se compartilhou com ela a proposta de continuação do trabalho com o paciente, pois se tinha localizado um tio a quem solicitar ajuda, para informar à família sobre a situação do filho.

Observou-se que, embora o paciente identificado tenha apontado à encaminhadora como uma pessoa significativa na sua história, ela se mostrou muito fragilizada e assustada, diante da possibilidade de participar da proposta de trabalho.Ou seja, podese ter alguém, para formar uma rede, motivado para ajudar, mas assustado com o trabalho a desenvolver.

Isto deixa em evidência o cuidado que se deve ter na seleção de pessoas da rede, estando atentos ao impacto que esse tipo de trabalho pode ter, destacando que nem toda pessoa pode fazer parte dela. Ou seja, do momento em que se pensa em estabelecer uma rede significativa, deve-se observar atentamente todos seus integrantes, devido à ressonância ou às conseqüências dessa proposta de trabalho.

No que se refere ao processo específico de intervenção de rede, reitera-se que uma vez detectada, o convite a seus integrantes é individual, feito pelo terapeuta/pesquisador. Após aceite, todas as reuniões com a rede acontecem de forma grupal.

\section{Considerações finais}

Ancorados nos delineamentos teóricos que sustentam o presente trabalho, observou-se que a cons- trução de redes nessa pesquisa girou em torno de no máximo seis pessoas e mínimo de cinco. A literatura diz que as mesmas podem ser redes consideradas pequenas ou médias, mas, é necessária uma análise mais detida, seja pelas características da proposta de intervenção, seja pelo contexto da atuação; ou seja a possibilidade de construção de redes, teria uma relação direta com as realidades culturais e políticas de saúde específicas.

Observou-se que no contexto público comunitário das realidades de atuação, e tendo a clínica como uma estratégia para pensar dilemas humanos nos seus contextos, era preciso trabalhar com o que é realmente possível. Por sua vez, é importante envidar esforços para a aceitação e reconhecimento da intervenção de rede, tanto pela equipe de saúde, quanto pela população.

Os casos analisados, assim como a prática nesta pesquisa, permitiram evidenciar este trabalho, como um caminho possível e eficaz na intervenção com rede pessoal significativa, o que se deu na medida em que foram geradas condições de mudança e de cuidado do outro, a partir das reais possibilidades de cada um, propiciando relações que implicaram em melhoria na qualidade de vida da pessoa objeto da construção da rede.

Outro aspecto de relevância a ser destacado com a utilização da intervenção da rede foi o da possibilidade concreta de distribuir as responsabilidades do trabalho de cuidado decorrentes do contexto de intervenção. Ou seja, o profissional sai do seu espaço e procura aliados na própria comunidade. Além disso, entende-se que o profissional que trabalha com as práticas de rede, deve ter como principal característica a de ser um catalisador e/ou um promotor de recursos e habilidades de cuidado do outro e de auto-cuidado.

Necessariamente a idéia de neutralidade e de ética do profissional precisa ser trazida à tona no trabalho com rede. A neutralidade tem que ser ancorada no trabalho específico de "criar condições", a todos os envolvidos na situação de atendimento, para facilitar a participação e conseguir que todas as partes tenham tanto "a escuta" como "a voz", garantidas na construção do processo. Quanto à Ética, acredita-se que a mesma faz parte do processo de reflexão constante que acompanha as ações, processo no qual convergem num mesmo nível ou intensidade, os valores profissionais expressos no código de ética, os 
das pessoas envolvidas no contexto de intervenção e no universo de valores pessoais. A partir da conjugação de todos esses elementos é que se configuram as bases para as escolhas que se deve fazer, para melhor abordar as queixas das pessoas.

Finalmente, destaca-se que, entrar em contacto com o potencial para a mudança presente nas pessoas, possibilita o desenvolvimento da promoção da saúde e resgate de potencialidades das envolvidas numa rede, trazendo à tona, principalmente, o sentimento de solidariedade presente em cada uma.

\section{Referências Bibliográficas}

Castel, R. (1984). La gestión de los riesgos. Barcelona: Anagrama.

Dabas, E. (1993). Red de redes: Las prácticas de intervención en redes sociales. Buenos Aires: Paidós.

Dabas, E. \& Najmanovich, D. (1995). Redes: El lenguaje de los vínculos. Hacia el fortalecimiento de la sociedad civil. Buenos Aires: Paidós.

Elkaïm, M. (1989). La práctica de la terapia de red. Barcelona: Gedisa.

Fucks, M. (1989). La corte de los milagros de Rosário. (mimeo).

Klefbek, J. (2000). Terapia de red: Un método de tratamiento en situaciones de crisis. Sistemas Familiares , v. 16, n.1, p. 47-78.

Lewin, K. (1952). Princípios de Psicologia Topológica, Trad. Alvaro Cabral. São Paulo: Cultrix.

Moré, C. L. O. O. (2000). Atendendo à demanda: proposta de um modelo de sistematização de intervenção psicológica junto a postos de saúde comunitários. Tese de Doutorado. Pontifícia Universidade Católica de São Paulo, São Paulo.

Moreno, J. L. (1951). Fondements de la Sociométrie Trad. Lesage e P. H. Mancorps. Paris: Presses Universitaires de France.

Packman, M.(1995). Redes: Una metáfora para la prática de intervención social. Buenos Aires: Paidós.

Sluzki, C. E. (1996). Novos Paradigmas de Cultura e Subjetividade. Porto Alegre: Artes Médicas.

Sluzki, C. E. (1997). A rede social na prática sistêmica: alternativas terapêuticas. São Paulo: Casa do Psicólogo.

Speck, V. R. (1989). La intervención en red social: Las terapias de red, teoria y desarrollo. Em La práctica de la terapia de red. Barcelona: Gedisa.

Strauss, A. L. \& Corbin, J. (1990). Grounded Theory Research: Procedures, Canons, and Evaluative Criteria. London: U. M. Press.

Vasconcelos, M. J. E. (1995).Terapia Familiar Sistêmica: Bases Cibernéticas. Campinas: Editorial Psy II. 